\title{
Animal models of optic nerve diseases
}

Eye (2004) 18, 1066-1074.

doi:10.1038/sj.eye.6701576

Optic nerve diseases are among the most devastating disorders in ophthalmology leading to retinal ganglion cell (RGC) degeneration, visual field loss and, potentially, blindness. The pathophysiologic mechanisms underlying optic neuropathies are not fully understood, although research in this area is substantial. Animal models are required in order to investigate the mechanism of each disease in detail, to improve our knowledge of how and why optic nerve axons die, and to test new treatment modalities. Developing an animal model for a disease, however, is usually complicated and challenging, and most experimental models are remote from the human disease.

There are several animal species that can be developed as suitable models for human disease. The advantage of using a monkey is its close phylogeny and high homology with humans. Monkeys have retinal and optic nerve anatomy that is nearly identical to human eyes. The validity of the experimental model, however, depends upon the degree to which it emulates the human condition, and a primate model is considered as having the closest compatibility for conducting research with the

Sam Rothberg Ophthalmic Molecular Biology Laboratory Goldschleger Eye Institute Sheba Medical Center Tel-Aviv University Tel-Hashomer, Israel

\section{Correspondence:}

H Levkovitch-Verbin, Goldschleger Eye Institute Sheba Medical Center Tel-Hashomer 52621, Israel Tel: 97235305828

Fax: 97235344480

E-mail: halevko@

hotmail.com

Received: 4 September 2003

Accepted: 4 September 2003 goal of understanding human diseases. Indeed, testing new treatment modalities in a monkey model is usually the last step before embarking upon clinical trials in humans. Unfortunately, monkeys are very expensive, their availability is limited, and they are difficult to handle. Experiments in monkeys require highly experienced teams and special housing facilities, making them beyond the reach of many research laboratories. Thus, rats and mice are commonly used to investigate optic nerve diseases. There is great conservation between rats, mice, and human genomes, which allows them to be widely used for research on human optic nerve disease. ${ }^{1}$ Rats are inexpensive, easy to house and handle, and their eyes, optic nerves, and superior colliculus are easily accessible. The structures of their optic nerve and retina, however, have a number of differences from those of humans: the eyes of rats and mice do not have maculae or foveae and $85-90 \%$ of their optic nerve axons decussate to the other side of the brain.

While rats are commonly used to study optic nerve injuries, the availability of a mouse model confers unique advantages. Genetic studies in mice are proving to be a potent means for learning about genes and pathologic mechanisms that cause disease. In addition, the genome of the mouse can be altered by adding transgenes or altering endogenous genes.

Laboratory mice live for approximately 2 years and often develop diseases that take decades to develop in humans. Models of optic nerve disease in the mouse can enable us to study the mechanism of RGC degeneration and potential new therapies using genetic manipulation in various transgenic and knockout mice that are not available in rats. ${ }^{2}$

In this review, the available animal models of the most common optic neuropathies will be described, including models for glaucoma, optic neuritis, anterior ischaemic optic neuropathy (AION), and traumatic optic neuropathies.

\section{Animal models of glaucoma}

An experimental model of glaucoma is useful for studying the effects of elevated intraocular pressure (IOP) on ocular tissues and for developing new therapeutic approaches to the disease. Since the IOP level is a major risk factor in human glaucoma, one experimental approach has been to increase IOP to a level that preferentially kills RGCs without causing ancillary injury to the retina and ocular structures. Cioffi and Sullivan ${ }^{3}$ have taken an alternative approach by inducing vasoconstriction in posterior orbital blood vessels by chronic pharmacological exposure. In the following review, the models used for the study of hypertensive glaucomatous optic neuropathy in monkeys, rats, and mice will be described. 


\section{Experimental glaucoma in monkeys}

While the most useful model for experimental glaucoma in monkeys is produced by argon laser photocoagulation treatment to the trabecular meshwork, diode laser photocoagulation was found to be effective as well. ${ }^{4}$ The former model was first suggested by Gaasterland and Kupfer $^{5}$ and later refined by Quigley and Hohman. ${ }^{6}$ In order to induce elevated IOP, monkeys are sedated and the laser beam is focused as precisely as possible on the centre of the mid-trabecular meshwork. Treatment should lead to whitening of the trabecular meshwork and often also to bubble formation. The recommended laser setting is a $50 \mu \mathrm{m}$ spot diameter, $1-1.5 \mathrm{~W}$, and a $0.5-\mathrm{s}$ duration. The number of required laser spots is between 80 and 250 in most eyes and repeated laser treatments are often needed. In this model, the treated eyes develop sustained, moderately elevated IOP with decreased outflow facility and optic nerve cupping such as that in human glaucoma. ${ }^{7,8}$ The rise in IOP usually appears a few days after the laser treatment and the IOP elevation usually lasts between days to more than a year, with the mean IOP varying between 25 and $60 \mathrm{mmHg}$. IOP can be measured under sedation and topical anaesthesia using the Goldman applanation tonometer. Optic nerve damage can be evaluated by stereoscopic ophthalmoscopy, fundus photographs, nerve fibre layer photographs (black and white), axonal counting by image analysis system, and RGC loss. Interestingly, visual field defects in monkeys can be detected by behavioural perimetry. ${ }^{9,10}$

A second model for producing chronic experimental glaucoma in primates was developed by Quigley and Addicks. ${ }^{11,12}$ In this model, extended IOP elevation was produced by injection of autologous, fixed red blood cells (RBC), and ghost red cells into the anterior chamber. Filling of the anterior chamber with blood, however, leads to the disadvantage of poor visibility on the optic nerve head and retina.

\section{Experimental glaucoma in rats}

While the monkey model of laser-induced IOP increase is robust and has been utilized by many laboratories, it has become too expensive for investigations that require large numbers of animals for testing the mechanisms of RGC death and its prevention. Consequently, rat models of experimental glaucoma were developed in order to provide a system for investigating the cell biology of pressure-induced optic neuropathy and potential neuroprotective strategies. In my experience, the translimbal laser photocoagulation model for glaucoma in rats is the most reliable, simple to produce, reproducible, and inexpensive model for experimental glaucoma in rats. ${ }^{13}$ Sustained increased IOP is achieved by treating the outflow channels of the rat eye through the peripheral cornea with a diode laser (Coherent Radiation, Clement-Ferrand, France) at $532 \mathrm{~nm}$ with a laser setting of $0.7 \mathrm{~s}, 0.4 \mathrm{~W}$, and a spot size of $50 \mu \mathrm{m}$ (Figure 1). The laser beam is delivered from a slit-lamp system without additional lenses and with the animal under general anaesthesia. The rat eye is rotated manually to allow the laser beam to be directed in a sharp angle to the trabecular meshwork (TM) (Figure 2). Treatment takes approximately $3 \mathrm{~min}$ per eye by an experienced researcher, therefore many rats can be treated in 1 day.

The laser treatment is given unilaterally and is repeated after a week if the IOP difference between the treated eye and the fellow eye is less than $6 \mathrm{mmHg}$. IOP is measured with the Tonopen XL in both eyes before and immediately after laser treatment, every 3-4 days in the first 2 weeks, and weekly thereafter. In all, 10 measurements are obtained for each eye from which the mean is calculated.

The retinal and choroidal blood vessels are observed by indirect ophthalmoscopy immediately after laser treatment. Particular attention needs to be paid to the patency of vessels and for signs of retinal oedema and haemorrhage. Following the laser treatment, IOP is increased in all eyes. The peak IOP is about $34-40 \mathrm{mmHg}$ and the IOP in the glaucomatous eyes is typically higher than the control eyes

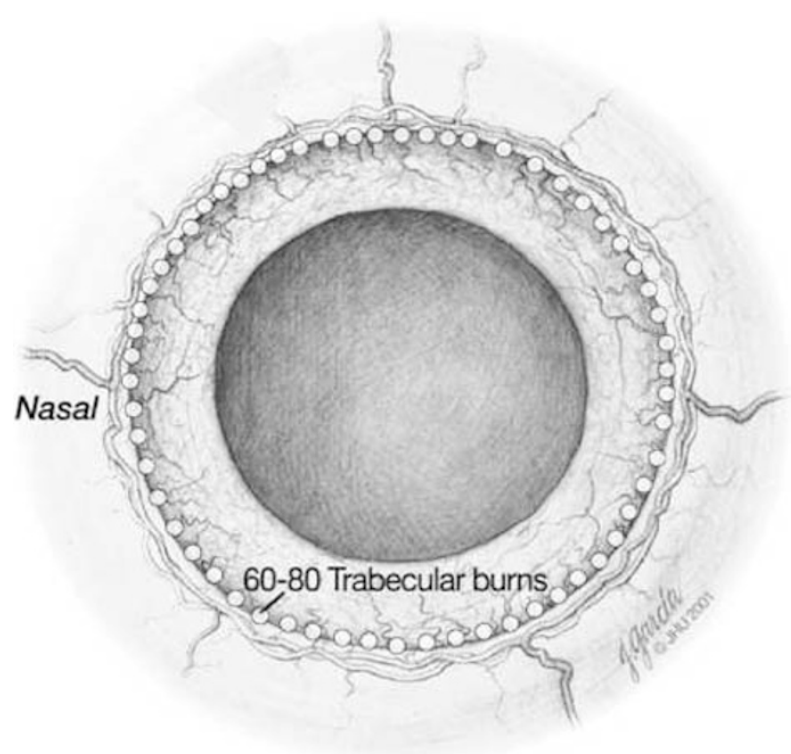

Figure 1 Translimbal laser photocoagulation model for glaucoma in rats. The recommended treatment is composed of 60-80 laser deliveries directed at the TM. Each circle represents an area of laser delivery. The laser treatment is given at $360^{\circ}$. Reprinted from Levkovitch-Verbin et al. Translimbal laser photocoagulation to the trabecular meshwork as a model of glaucoma in rats. Invest Ophthalmol Vis Sci 2002; 43(2): 402-410. 
for at least 3 weeks. In this model, the mean axonal loss at 3 weeks is about $20 \%$, at 6 weeks it rises to $25 \%$, and at 9 weeks it reaches about $50 \%$ (Figure 3). The laser treatment leads to closure of the intertrabecular spaces and of the major outflow channels. The retina and choroid continue to appear normal on ophthalmoscopy at all times after treatment. Light microscopic examination shows only loss of RGCs and their nerve fibres.

There are three additional currently available models for experimental glaucoma in rats, but all of them are more time consuming and technically more difficult to reproduce than the laser photocoagulation model.

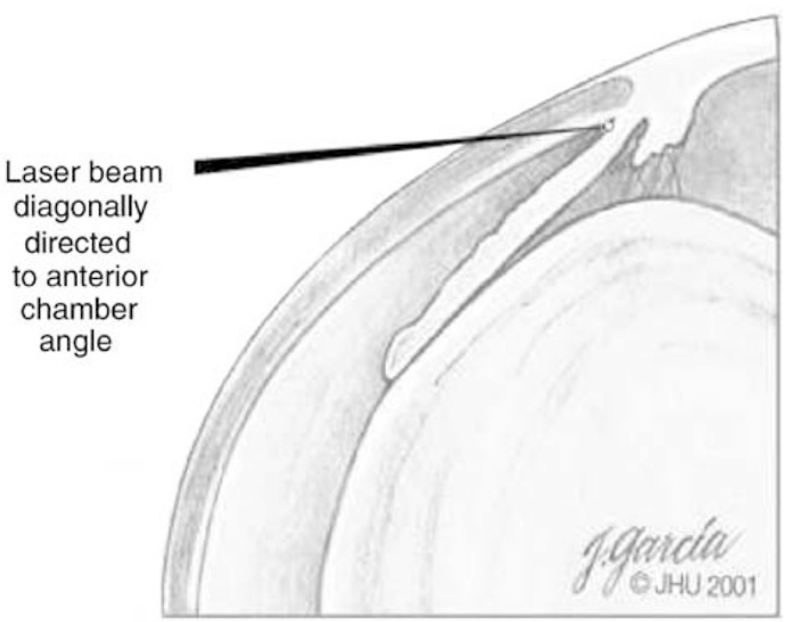

Figure 2 Schematic diagram of the rat anterior chamber illustrating the direction of the laser beam using the translimbal laser photocoagulation model for glaucoma in rats. The laser beam is focused to achieve maximum power density at the anterior chamber angle. Reprinted from Levkovitch-Verbin $e t$ al. Translimbal laser photocoagulation to the trabecular meshwork as a model of glaucoma in rats. Invest Ophthalmol Vis Sci 2002; 43(2): 402-410.
Morrison and co-workers ${ }^{14-16}$ increased rat IOP by hyperosmotic saline microinjection into the episcleral veins of Brown-Norway rats in order to increase the outflow resistance. Using a microneedle injection apparatus, a volume of $50 \mu \mathrm{l}$ micro-filtered hypertonic saline solution $(\mathrm{NaCl})$ was injected into the limbal vascular plexus. This was sufficient for about $50 \%$ of rats to develop elevated IOP, even though most animals needed repeated injections. The advantage of using Brown-Norway rats is that IOP can be measured by a Tonopen $-\mathrm{XL}$ on awake animals. ${ }^{17}$ General anaesthetics were shown to have resulted in a rapid and substantial decrease in IOP in all eyes, and so measurements of IOP in awake animals provide the most accurate documentation of IOP history for rat glaucoma model studies. ${ }^{18}$

Shareef and colleagues ${ }^{19,20}$ cauterized large veins draining the anterior rat eye and used the pneumatonograph to estimate the IOP. In order to produce an increased IOP, the limbus-draining veins were exposed by incising the conjunctiva. Cautery was applied to two large veins per eye, completely blocking the venous return through each vein. This procedure usually caused an increase in IOP that was twice the normal level and did so for a long time. At 6 months, there was about a $40 \%$ loss of RGCs. The RGC death was proved to occur via apoptosis. ${ }^{21}$ According to the authors, cauterizing more veins led to a further increase in IOP.

Another rodent model for chronic glaucoma was developed by Ueda et al. ${ }^{22}$ They injected India ink into the anterior chamber 1 week prior to laser photocoagulation treatment. Increased IOP was achieved in all rats within 4 weeks and optic nerve damage developed as well.

Optic nerve damage in rats can be assessed either by counting optic nerve axons or the number of RGCs. For axonal counting, cross-sections of the optic nerve from

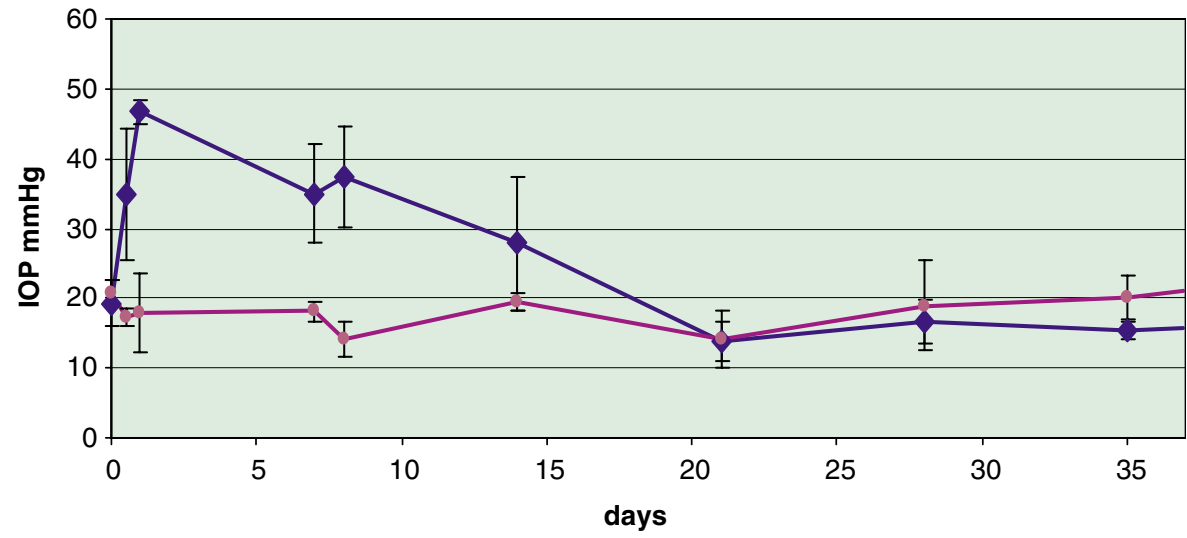

Figure 3 Time course of IOP in eyes treated by the translimbal photocoagulation glaucoma model in rats. The IOP is elevated by the first $24 \mathrm{~h}$ after the laser treatment and returns to baseline at about 3 weeks. Reprinted from Levkovitch-Verbin et al. Translimbal laser photocoagulation to the trabecular meshwork as a model of glaucoma in rats. Invest Ophthalmol Vis Sci 2002; 43(2): 402-410. 
the glaucomatous eye and control fellow eye are analysed by an image analysis system in order to measure the density and fibre diameter distributions and to calculate the total number of axons in each nerve. RGC loss can be evaluated by retrograding labelling with a dye tracer (Figure 4). Labelling of the RGCs can be performed either by applying a dye to a cut in the orbital optic nerve or to the superior colliculus. Either way, the dye labels the RGCs by retrograde axonal flow. Rhodamine Dextran (Molecular Probes, Eugene, OR, USA) is commonly used for labelling the RGCs by applying its crystals to a cut edge of the nerve $2-3 \mathrm{~mm}$ behind the globe. This method can be used only unilaterally because it blinds the treated eye. Fluorogold (Fluorochrome, Inc., Denver, CO, USA) is commonly used for labelling through the superior colliculus. This method can be performed bilaterally so that both sides of the retina will be labelled; however, labelling through the superior colliculus is more time consuming. For counting the RGCs, the retinas should be prepared as whole mounts and viewed through a fluorescence microscope with an appropriate filter.

\section{Experimental glaucoma in mice}

With recent advances in genetic manipulation, the development of experimental glaucoma in mice became a matter of high priority. One of the main obstacles was measuring IOP in the mouse eye. One procedure for doing so involves direct measurement of pressure after cannulation of the anterior chamber. ${ }^{23}$ Although this technique is reliable and accurate, it is invasive and difficult to repeat in the same experimental eye. Several devices were recently developed to measure IOP in a noninvasive way, all claiming to have the ability to measure IOP accurately in mice. Some use the Tonopen without the ocufilm cover, ${ }^{24}$ while others use a modified Goldmann tonometer, both with reliable results. ${ }^{25}$ There are other newly developed devices, such as the silicone MEMS-based (micro-electric-mechanical systems) fibre optic pressure sensor ${ }^{26}$ and the rebound tonometer, adapted specifically for mice. ${ }^{27}$

Once measurement of the IOP in mice became available and reliable, several models for glaucoma in mice were developed, all claiming to be reproducible and reliable. The one designed by Mabuchi et $a l^{28}$ used the limbal laser photocoagulation technique to induce elevated IOP with glaucomatous optic nerve damage in mice. The duration of increased IOP ranged from 2 to 12 weeks and the mean IOP was 1.5-fold higher in the treated eye compared to controls. There was also a positive relationship between the magnitude and duration of elevated IOP and axonal loss. McKinnon et $a l^{24}$ found that the Morrison model for glaucoma in rats

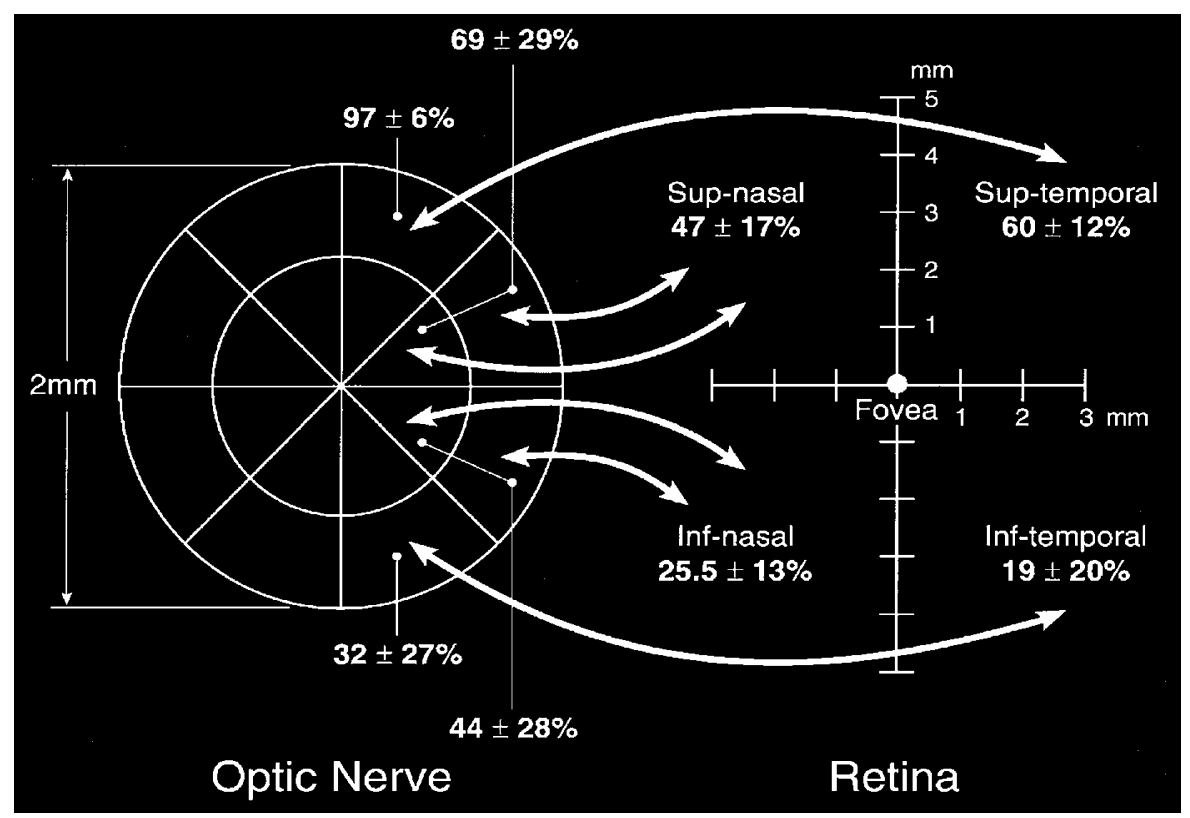

Figure 4 Diagram comparing RGC density loss in transection eyes for four areas of the retina (right) with the corresponding zones of the optic nerve into which axons of each group of RGCs project (arrows). There is a general correlation between RGC density decrease and axonal loss, being greatest in the superotemporal retina (upper temporal nerve) and lowest in the inferotemporal retina (lower temporal nerve). The data represent one left eye. Reprinted from Levkovitch-Verbin et al. A model to study differences between primary and secondary degeneration of retinal ganglion cells in rats by partial optic nerve transaction. Invest Ophthalmol Vis Sci 2003; 44(8): 3388-3393. 
using the limbal injections of hyperosmotic saline can also work well in mice: the mean axonal loss in this model was $20 \%$ after 8 weeks. ${ }^{24}$

Another model that has become well established over the past few years was developed by John et al. ${ }^{2,29}$ It consists of the mouse strain DBA/2J that develops glaucoma subsequent to anterior chamber changes. The glaucoma in the DBA/2J mice shares similarities with pigmentary dispersion glaucoma in humans. These mice develop pigment dispersion, iris transillumination, iris atrophy, anterior synechia, and elevated IOP. The prevalence and severity increase with age, followed by RGC death, and optic nerve degeneration. Two chromosomal regions, one on chromosome 6 and one on chromosome 4 , contribute to this glaucoma model. ${ }^{30}$ Recently, John and his group ${ }^{31}$ generated and studied mouse models with mutations in genes that are responsible for anterior segment dysgenesis anomalies in humans. Developing these mouse models supports the search for mutations in specific human candidate genes. Although these models are specific for unique types of glaucoma, they can be used to test the mechanism of RGC death in glaucoma as well as to evaluate new treatment modalities.

\section{Experimental model for optic neuritis}

The optic nerve is a frequent site of involvement in multiple sclerosis (MS), and optic neuritis often appears as the presenting sign of MS. Many attempts have been made to create animal models of demyelinating optic neuritis, such as that found in MS, using autoimmunity or virus infection. ${ }^{32-35}$ The myelin sheath of the nerve is composed mainly of proteolipid protein (PLP) and myelin basic protein (MBP), while the myelin oligodendrocyte glycoprotein (MOG) comprises only $0.01-0.05 \%$ of the total amount of myelin protein. It has been shown that the injection of whole brain homogenate, a purified preparation of MBP, PLP, or MOG, may cause experimental allergic encephalomyelitis (EAE). EAE is a T-cell-mediated, inflammatory autoimmune disorder with demyelination of the central nervous system (CNS) that has been frequently used as an animal model for the human MS. ${ }^{36,37}$ As in human MS, there is loss of myelin sheaths that envelop axons and these naked axons can be identified. Other features of optic neuritis in EAE include optic disc oedema, cellular infiltrate that predominantly involves the retrobulbar optic nerve, and blood-brain barrier disruption. It is now believed that immunization with MOG produces a chronic form of EAE, referred to as chronic relapsing EAE, in which animals go through multiple episodes of relapses and remissions, a clinical picture that better mimics MS. ${ }^{38,39}$ Furthermore, it has been demonstrated that by using different immunization protocols and proper rat strains subforms of MS can be reproducibly induced. ${ }^{40}$

EAE can be induced in a number of experimental laboratory animals, including primates, rats, and mice. PLP, MBP, and MOG need to be synthesized and injected subcutaneously in order to induce EAE. Clinical signs of EAE will begin to develop a few days after the first injection, and it is essential to followup the animals using the clinical score for EAE.

These models are now being used for developing novel therapeutics for MS. ${ }^{41}$

\section{Experimental models for traumatic optic neuropathy}

Traumatic optic nerve lesions are usually the consequence of a severe blunt head trauma, often a frontal blow severe enough to cause loss of consciousness. Prognosis for the recovery of vision is still poor. Nevertheless, animal models for traumatic optic neuropathy are often used, mostly because they are easy to perform and can be well standardized. In this review, models of optic nerve transection (axotomy) and crush injury are discussed.

\section{Optic nerve transection}

In rats, optic nerve transection is usually performed using an intraorbital approach. ${ }^{42}$ Using a binocular operating microscope, the superior conjunctiva is incised, the muscles and connective tissue are separated, and the intraorbital optic nerve is exposed. A blade knife is used to transect the optic nerve behind the globe, taking care not to interfere with the blood supply and sparing the meningeal sheaths. At the end of the procedure, the retinas should be examined ophthalmoscopically to assure blood vessel patency.

RGCs degenerate rapidly after optic nerve transection. ${ }^{42-44}$ One-half of them will degenerate 4 days after optic nerve axotomy, and it rises to about $70 \%$ in 1 week and to more than $95 \%$ in 2 weeks.

A special model for optic nerve transection in rats was developed by Solomon et $a l^{45}$ in which special care was taken to preserve the vasculature and to retain the continuity of the meninges in order to avoid neuroma formation and to allow the injections of substances into the meningeal tube and the regeneration of transected axons. In this model, the rat orbital optic nerve is exposed by a lateral canthotomy, incision of the conjunctiva, and a nasal rotation of the globe by a fixating suture. After separating the surrounding tissue around the nerve, an opening is made in the neural meninges by a glass dissector with a sharp tip. The nerve is completely transected through this opening by moving 
the tip of the dissector horizontally from side to side, while introducing it slowly throughout the depth of the nerve until the whole width is traversed.

In monkeys, the optic nerve is transected by a lateral approach through the skin and the bone of the orbit approximately $6 \mathrm{~mm}$ posterior to the globe. The rate of RGC degeneration in this model is usually slower, with about a $70 \%$ loss at 1 month and a $90 \%$ loss at 2 months.

\section{Crush injury in rats and mice}

Crush injury can be performed using an intra-orbital ${ }^{47}$ or intracranial approach, ${ }^{48}$ the former being easier to perform and less time consuming. The crush injury can be inflicted by forceps, balloon, or other devices. The intra-orbital technique with forceps is the one most commonly used. ${ }^{44,49}$ With the aid of a binocular operating microscope, the conjunctiva is incised and the optic nerve is exposed. The crush injury is inflicted for $1 \mathrm{~s}$ by a cross-action forceps $2-3 \mathrm{~mm}$ from the eyeball, taking special care not to interfere with the blood supply. This method can be used in rats and mice, although entering the mouse orbit can be more difficult due to the blood plexus surrounding the globe. Our group found that the mean survival of RGCs after severe crush injury for $1 \mathrm{~s}$ in the wild-type mouse (CB6F) was $47 \%$ at 1 week, $27 \%$ at 2 weeks, and $8 \%$ at 8 weeks. ${ }^{50}$

The inability to calculate the force applied upon the forceps to achieve the crush injury is a drawback. Recently, Gellrich et $a l^{51}$ developed a calibrated traumatic optic nerve injury model using a microinjury device based on a small dynamometer mounted on a conventional micromanipulator: the parameters of force and time can now be precisely monitored during the experiment. $^{51}$

\section{Ischaemic optic neuropathy}

\section{Anterior ischaemic optic neuropathy}

Recently, an animal model for anterior ischaemic optic neuropathy (AION) in rats and mice was developed by Bernstein et al. ${ }^{52-54}$ In this model, a photosensitizing agent is injected intravenously into anaesthetized rats. Using a custom-designed fundus contact lens, a laser beam directly activates the dye within the small vessels perfusing the optic nerve while sparing the large calibre vessels perfusing the inner retina. Pale oedema of the optic nerve appears shortly thereafter.

Electrophysiologically, there is a decrease in amplitude and, histologically, there is impairment in axonal transport. The mean RGC loss by 39 days after the treatment is $40 \%$. A similar model was developed for use in mice.

\section{Experimental models for secondary degeneration}

In the CNS, injury from various primary lesions, such as ischaemia and trauma, can lead to widespread damage to neurons beyond the initial injury site. ${ }^{55,56}$ This phenomenon is known as secondary degeneration and can, therefore, result in greater loss of tissue than that caused by the initial disorder. Moreover, it may continue for an extended period of time after termination of the primary event. Two known models for secondary degeneration in the optic nerve were developed by Schwartz et $a l^{57}$ and by our group..$^{58,59}$

\section{Partial crush injury of the rat optic nerve}

Yoles and Schwartz ${ }^{57}$ developed the first model of secondary degeneration in the optic nerve. A crush injury is inflicted on the orbital optic nerve $2 \mathrm{~mm}$ behind the globe using calibrated cross-action forceps that can inflict different levels of severity of lesions by varying the number of screw revolutions attached to the forceps. Primary damage can be measured by immediate labelling of the RGCs with a neurotracer distal to the site of injury. Only intact axons will transport the dye. Secondary degeneration is measured by the application of dye distal to the injury site at various time points after the primary injury, assuming that only intact axons that survived the primary lesion and secondary degeneration will transport the dye. Secondary degeneration is calculated as the percentage of neurons that had degenerated subsequent to the primary damage. This model is useful for investigating the role of different treatment strategies, but it cannot be used to study the cellular and molecular mechanism of secondary degeneration compared to primary degeneration because primary and secondary degenerating axons and RGCs are located close to each other and are not separated morphologically.

\section{Partial transection model for secondary degeneration}

We developed a model for secondary degeneration in monkeys and rats using partial transection of the optic nerve. ${ }^{58,59}$ In this model, the upper third of the intraorbital nerve is transected, causing initially primary degeneration of the upper optic nerve and the corresponding RGC in the upper retina. The basis for this model is the known topographic separation of RGC in the primate and rodent retina. In the primate, RGC bodies are separated into upper and lower retinal zones that are divided by a horizontal raphe. The RGCs with cell bodies that are relatively close together above and below the raphe send their axons into the upper and lower poles of the optic nerve, respectively. In our 
monkey experiment, we cut the superior one-third of the optic nerve, and this led to the primary degeneration of most RGCs in the superior retina. Our assumption was that RGCs of the inferior retina would be unaffected unless secondary degeneration had occurred.

Interestingly, there was also significant loss of RGCs in the inferior retina, whose axons had not been cut. At 3 months after the injury, partial transection of the optic nerve caused a loss of $55 \pm 13 \%$ of RGC bodies in the superior retina and a $22 \pm 10 \%$ RGCs loss in the inferior retina that was not directly injured by transection. The loss of superior optic nerve axons was $83 \pm 12 \%$, while the inferior loss was $34 \pm 20 \%$. We showed that secondary degeneration occurs in the optic nerve of primates and that it may potentially contribute to other optic nerve neuropathies, such as glaucoma.

Our model allowed for more precise separation of directly injured RGCs from RGCs that had died without direct insult. This feature makes it useful for studying the magnitude, distribution, and the selectivity, as well as the differential mechanisms of secondary neuronal degeneration. Since the expense of using monkeys precludes large-scale testing of treatments for secondary degeneration, we developed a similar model in the optic nerve of rats. ${ }^{59}$ The technical difficulty of reliably cutting the same portion of the superior nerve was overcome through specially designed instrumentation. With a rodent model, large numbers of animals can be studied to allow careful delineation of the nature of secondary degeneration after the death of neighbouring neurons.

\section{Experimental models for mitochondrial optic neuropathy}

Increasing evidence shows that Leber's hereditary optic neuropathy $(\mathrm{LHON})$ is a neurodegenerative disease linked to mitochondrial dysfunction. Deficiencies in respiratory chain reaction and reactive oxygen species are believed to play pivotal roles in the pathogenesis of LHON. LHON, a maternally inherited disease, is the most common cause of blindness in otherwise healthy young men. It manifests as acute or subacute bilateral central vision loss associated with optic nerve and RGC degeneration. Two animal models for mitochondrial optic neuropathy were recently developed in mice. Zhang et $a l^{60}$ found that intravitreal injections of rotenone, a natural pesticide that inhibits mitochondrial complex I, caused RGC loss similar to that found in LHON. In another model, Qi et al ${ }^{61}$ found that injections of recombinant adeno-associated virus vector expressing ribozyme targeted against superoxide dismutase 2 (SOD2) mRNA into the eyes of DBA/1J mice increase the mitochondrial levels of reactive oxygen species. The adeno-associated virus expressing ribozyme led to the loss of axons and myelin in the optic nerve and RGCs in the retina as with LHON.

\section{References}

1 Paigen K. A miracle enough: the power of mice. Nature Med 1995; 1: 215-220.

2 John SW, Anderson MG, Smith RS. Mouse genetics: a tool to help unlock the mechanisms of glaucoma. J Glaucoma 1999; 8(6): 400-412.

3 Cioffi GA, Sullivan P. The effect of chronic ischemia on the primate optic nerve. Eur J Ophthalmol 1999; 9(Suppl 1): S34-S36.

4 Wang RF, Schumer RA, Serle JB, Podos SM. A comparison of argon laser and diode laser photocoagulation of the trabecular meshwork to produce the glaucoma monkey model. J Glaucoma 1998; 7(1): 45-49.

5 Gaasterland D, Kupfer C. Experimental glaucoma in the rhesus monkey. Invest Ophthalmol 1974; 13(6): 455-457.

6 Quigley HA, Hohman RM. Laser energy levels for trabecular meshwork damage in the primate eye. Invest Ophthalmol Vis Sci 1983; 24(9): 1305-1307.

7 Quigley HA, Nickells RW, Kerrigan LA, Pease ME, Thibault DJ, Zack DJ. Retinal ganglion cell death in experimental glaucoma and after axotomy occurs by apoptosis. Invest Ophthalmol Vis Sci 1995; 36(5): 774-786.

8 Quigley HA. Experimental glaucoma damage mechanism. Arch Ophthalmol 1983; 101(8): 1301-1302.

9 Harwerth RS, Smith III EL, DeSantis L. Behavioral perimetry in monkeys. Invest Ophthalmol Vis Sci 1993; 34(1): $31-40$

10 Harwerth RS, Smith III EL, DeSantis L. Experimental glaucoma: perimetric field defects and intraocular pressure. J Glaucoma 1997; 6(6): 390-401.

11 Quigley HA, Addicks EM. Chronic experimental glaucoma in primates. I. Production of elevated intraocular pressure by anterior chamber injection of autologous ghost red blood cells. Invest Ophthalmol Vis Sci 1980; 19(2): 126-136.

12 Quigley HA, Addicks EM. Chronic experimental glaucoma in primates. II. Effect of extended intraocular pressure elevation on optic nerve head and axonal transport. Invest Ophthalmol Vis Sci 1980; 19(2): 137-152.

13 Levkovitch-Verbin H, Quigley HA, Martin KR, Valenta D, Baumrind LA, Pease ME. Translimbal laser photocoagulation to the trabecular meshwork as a model of glaucoma in rats. Invest Ophthalmol Vis Sci 2002; 43(2): 402-410.

14 Johnson EC, Morrison JC, Farrell S, Deppmeier L, Moore CG, McGinty MR. The effect of chronically elevated intraocular pressure on the rat optic nerve head extracellular matrix. Exp Eye Res 1996; 62(6): 663-674.

15 Morrison J, Farrell S, Johnson E, Deppmeier L, Moore CG, Grossmann E. Structure and composition of the rodent lamina cribrosa. Exp Eye Res 1995; 60(2): 127-135.

16 Morrison JC, Moore CG, Deppmeier LM, Gold BG, Meshul CK, Johnson EC. A rat model of chronic pressure-induced optic nerve damage. Exp Eye Res 1997; 64(1): 85-96.

17 Moore CG, Epley D, Milne ST, Morrison JC. Long-term noninvasive measurement of intraocular pressure in the rat eye. Curr Eye Res 1995; 14(8): 711-717.

18 Jia L, Cepurna WO, Johnson EC, Morrison JC. Effect of general anesthetics on IOP in rats with experimental 
aqueous outflow obstruction. Invest Ophthalmol Vis Sci 2000; 41(11): 3415-3419.

19 Sawada A, Neufeld AH. Confirmation of the rat model of chronic, moderately elevated intraocular pressure. Exp Eye Res 1999; 69(5): 525-531.

20 Shareef SR, Garcia-Valenzuela E, Salierno A, Walsh J, Sharma SC. Chronic ocular hypertension following episcleral venous occlusion in rats. Exp Eye Res 1995; 61(3): 379-382.

21 Garcia-Valenzuela E, Shareef S, Walsh J, Sharma SC. Programmed cell death of retinal ganglion cells during experimental glaucoma. Exp Eye Res 1995; 61(1): 33-44.

22 Ueda J, Sawaguchi S, Hanyu T, Yaoeda K, Fukuchi T, Abe H et al. Experimental glaucoma model in the rat induced by laser trabecular photocoagulation after an intracameral injection of India ink. Jpn J Ophthalmol 1998; 42(5): 337-344.

23 John SW, Hagaman JR, MacTaggart TE et al. Intraocular pressure in inbred mouse strains. Invest Ophthalmol Vis Sci 1997; 38(1): 249-253.

24 McKinnon SJ, Reitsamer HA, Ransom NL, Caldwell M, Harrison JM, Kiel JW. Induction and tonopen measurement of ocular hypertension in C57BL/6 mice. ARVO abstract, poster 3319, 2003.

25 Cohan BE, Bohr DF. Measurement of intraocular pressure in awake mice. Invest Ophthalmol Vis Sci 2001; 42(11): 2560-2562.

26 Ahmed E, Ma J, Rigas I et al. Non-invasive tonometry in the mouse. ARVO abstract, poster 3336, 2003.

27 Danias J, Kontiola AI, Filippopoulos T, Mittag T. Method for the noninvasive measurement of intraocular pressure in mice. Invest Ophthalmol Vis Sci 2003; 44(3): 1138-1141.

28 Mabuchi F, Aihara M, Lindsey R, Weinreb R. Mouse optic nerve axon loss is related to magnitude and duration of laser-induced ocular hypertension. ARVO abstract, poster 3333, 2003.

29 John SW, Smith RS, Savinova OV, Hawes NL, Chang B, Turnbull D et al. Essential iris atrophy, pigment dispersion, and glaucoma in DBA/2J mice. Invest Ophthalmol Vis Sci 1998; 39(6): 951-962.

30 Chang B, Smith RS, Hawes NL et al. Interacting loci cause severe iris atrophy and glaucoma in DBA/2J mice. Nat Genet 1999; 21(4): 405-409.

31 Gould DB, John SW. Anterior segment dysgenesis and the developmental glaucomas are complex traits. Human Molecular Genesis 2002; 11(10): 1185-1193.

32 Gold R, Hartung HP, Toyka KV. Animal models for autoimmune demyelinating disorders of the nervous system. Mol Med Today 2000; 6(2): 88-91.

33 Genain CP, Hauser SL. Experimental allergic encephalomyelitis in the New World monkey. Callithrix jacchus Immunol Rev 2001; 183: 159-172.

34 Barac-Latas V, Suchanek G, Breitschopf H, Stuehler A, Wege $\mathrm{H}$, Lassmann H. Patterns of oligodendrocyte pathology in coronavirus-induced subacute demyelinating encephalomyelitis in the Lewis rat. Glia 1997; 19(1): $1-12$.

35 Owens T, Sriram S. The immunology of multiple sclerosis and its animal model, experimental allergic encephalomyelitis. Neurol Clin 1995; 13(1): 51-73.

36 Raine CS, Traugott U, Nussenblatt RB, Stone SH. Optic neuritis and chronic relapsing experimental allergic encephalomyelitis: relationship to clinical course and comparison with multiple sclerosis. Lab Invest 1980; 42(3): 327-335.
37 Rao NA. Chronic experimental allergic optic neuritis. Invest Ophthalmol Vis Sci 1981; 20(2): 159-172.

38 Adelmann M, Wood J, Benzel I et al. The N-terminal domain of the myelin oligodendrocyte glycoprotein (MOG) induces acute demyelinating experimental autoimmune encephalomyelitis in the Lewis rat. J Neuroimmunol 1995; 63(1): 17-27.

39 Amor S, Groome N, Linington C, Morris MM, Dornmair K, Gardinier MV et al. Identification of epitopes of myelin oligodendrocyte glycoprotein for the induction of experimental allergic encephalomyelitis in SJL and Biozzi $\mathrm{AB} / \mathrm{H}$ mice. J Immunol 1994; 153(10): 4349-4356.

40 Storch MK, Stefferl A, Brehm U, Weissert R, Wallstrom E, Kerschensteiner $\mathrm{M}$ et al. Autoimmunity to myelin oligodendrocyte glycoprotein in rats mimics the spectrum of multiple sclerosis pathology. Brain Pathol 1998; 8(4): 681-694.

41 Fisher J, Levkovitch-Verbin H, Schori H, Yoles E, Butovsky $\mathrm{O}$, Kaye JF et al. Vaccination for neuroprotection in the mouse optic nerve: implications for optic neuropathies. $J$ Neurosci 2001; 21(1): 136-142.

42 Berkelaar M, Clarke DB, Wang YC et al. Axotomy results in delayed death and apoptosis of retinal ganglion cells in adult rats. J Neurosci 1994; 14(7): 4368-4374.

43 Garcia-Valenzuela E, Gorczyca W, Darzynkiewicz Z, Sharma SC. Apoptosis in adult retinal ganglion cells after axotomy. J Neurobiol 1994; 25(4): 431-438.

44 Villegas-Perez MP, Vidal-Sanz M, Rasminsky M, Bray GM, Aguayo AJ. Rapid and protracted phases of retinal ganglion cell loss follow axotomy in the optic nerve of adult rats. $J$ Neurobiol 1993; 24(1): 23-36.

45 Solomon AS, Lavie V, Hauben U, Monsonego A, Yoles E, Schwartz M. Complete transection of rat optic nerve while sparing the meninges and the vasculature: an experimental model for optic nerve neuropathy and trauma. J Neurosci Methods 1996; 70(1): 21-25.

46 Agapova OA, Kaufman PL, Lucarelli MJ et al. Differential expression of matrix metalloproteinases in monkey eyes with experimental glaucoma or optic nerve transection. Brain Res 2003; 967(1-2): 132-143.

47 Duvdevani R, Rosner M, Belkin M et al. Graded crush of the rat optic nerve as a brain injury model: combining electrophysiological and behavioral outcome. Rest. Neurol. Neurosci. 1990; 2: 31-38.

48 Chierzi S, Strettoi E, Cenni MC, Maffei L. Optic nerve crush: axonal responses in wild-type and bcl-2 transgenic mice. $J$ Neurosci 1999; 19(19): 8367-8376.

49 Yoles E, Wheeler LA, Schwartz M. Alpha2-adrenoreceptor agonists are neuroprotective in a rat model of optic nerve degeneration. Invest Ophthalmol Vis Sci 1999; 40(1): 65-73.

50 Levkovitch-Verbin H, Harris-Cerruti C, Groner Y, Wheeler LA, Schwartz M, Yoles E. RGC death in mice after optic nerve crush injury: oxidative stress and neuroprotection. Invest Ophthalmol Vis Sci 2000; 41(13): 4169-4174.

51 Gellrich NC, Schimming R, Zerfowski M, Eysel UT. Quantification of histological changes after calibrated crush of the intraorbital optic nerve in rats. Br J Ophthalmol 2002; 86(2): 233-237.

52 Bernstein SL, Yan G, Nguyen A, Flower R, Kelman SE, Johnson MA. A true model of anterior ischemic optic neuropathy (AION). ARVO abstract, poster 5019, 2001.

53 Goldenberg-Cohen N, Margolis F, Miller N, Bernstein S. Functional changes in a mouse model of anterior ischemic optic neuropathy. ARVO abstract, poster 3677, 2002. 
54 Goldenberg-Cohen N, Miller NR, Guo Y, Margolis F, Bernstein SL. Anterior ischemice optic neuropathy alters RGC and oligodendrocyte function. ARVO abstract, poster 4556, 2003.

55 Crowe MJ, Bresnahan JC, Shuman SL, Masters JN, Beattie MS. Apoptosis and delayed degeneration after spinal cord injury in rats and monkeys. Nature Med 1997; 3(1): 73-76.

56 Dusart I, Schwab ME. Secondary cell death and the inflammatory reaction after dorsal hemisection of the rat spinal cord. Eur J Neurosci 1994; 6(5): 712-724.

57 Yoles E, Schwartz M. Degeneration of spared axons following partial white matter lesion: implications for optic nerve neuropathies. Exp Neurol 1998; 153(1): 1-7.

58 Levkovitch-Verbin H, Quigley HA, Kerrigan-Baumrind LA, D'Anna SA, Kerrigan D, Pease ME. Optic nerve transection in monkeys may result in secondary degeneration of retinal ganglion cells. Invest Ophthalmol Vis Sci 2001; 42(5): 975-982.

59 Levkovitch-Verbin H, Quigley HA, Martin KR, Zack DJ, Pease ME, Valenta DF. A model to study differences between primary and secondary degeneration of retinal ganglion cells in rats by partial optic nerve transection. Invest Ophthalmol Vis Sci 2003; 44(8): 3388-3393.

60 Zhang X, Jones D, Gonzalez-Lima F. Mouse model of optic neuropathy caused by mitochondrial complex I dysfunction. Neurosci Lett 2002; 326(2): 97-100.

61 Qi X, Lewin AS, Hauswirth WW, Guy J. Optic neuropathy induced by reductions in mitochondrial superoxide dismutase. Invest Ophthalmol Vis Sci 2003; 44(3): 1088-1096. 